\title{
The effects of gain- and loss-framed nutritional messages on children's healthy eating behaviour
}

\author{
Alice Binder ${ }^{1, *}$, Brigitte Naderer ${ }^{1,2}$ and Jörg Matthes ${ }^{1}$ \\ 'Department of Communication, Advertising and Media Effects Research Group, University of Vienna, Währingerstr. \\ 29, 1090 Vienna, Austria: ${ }^{2}$ Department of Media and Communication, Ludwig-Maximilians-University Munich, \\ Oettingenstr., 6780538 Munich, Germany
}

Submitted 18 June 2019: Final revision received 19 0ctober 2019: Accepted 7 November 2019: First published online 20 April 2020

\begin{abstract}
Objective: Despite extensive research on framing effects in public health communication, there is still a lack of knowledge on how gain frames $v$. loss frames can encourage healthy eating behaviour among children.

Design: Drawing on the Prospect Theory as well as on the Reactivity of Embedded Food Cues in Advertising Model, an experiment exposed children to an audiovisual cartoon movie with gain-framed nutritional messages about eating fruit (gain condition), loss-framed nutritional messages about eating fruit (loss condition) or a message without any food (control group). Children's fruit intake was measured as the dependent variable. Children's awareness of gain- and loss-framed arguments was treated as mediators, while children's age and parents' self-reported foodrelated mediation styles were modelled as moderators.

Setting: Vienna, Austria, in 2018.

Participants: Children aged 6-10 years ( $N 161)$.

Results: Children in the gain frame group were more aware of gain-framed arguments, and children in the loss frame group were more aware of loss-framed arguments than those in the control group. However, only the mediator awareness of gain-framed arguments increased fruit intake. Additionally, there was a direct effect of the gain-framed message on fruit intake compared to the control group. The loss condition did not reveal such an effect. Neither parent's food-related mediation styles nor children's age moderated those results.

Conclusion: Gain-framing seems to be more effective in influencing children's healthy food choices compared to loss-framing. Implications for health communication strategies aimed at children are discussed.
\end{abstract}

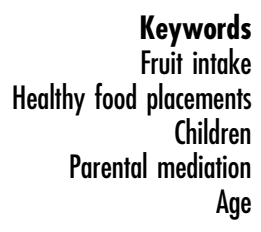

According to the World Health Organization ${ }^{(1)}$, fruit is a crucial component of a healthy, balanced diet, and consuming five portions of fruit or vegetables per day can dramatically reduce the risk of chronic disease ${ }^{(2)}$. Researchers have also shown that children and adolescents who eat fruit have lower BMI than the ones who do not, and are thus less susceptible to overweight and obesity ${ }^{(3)}$. Because obesity and overweight in children are critical health concerns worldwide $^{(1,4,5)}$ and children generally do not eat the proposed fruit portions by day ${ }^{(6)}$, it is crucial to gain insights into ways of increasing children's consumption of fruit.

Research has indicated that watching movies and TV shows, which ranks among children's favourite pastimes ${ }^{(7)}$, can affect children's food choices, at least their unhealthy ones $^{(8-14)}$. Although such findings suggest that movies and TV shows can serve as positive means of increasing children's healthy food preferences, studies on healthy food placements and their impact on children's food choices remain scarce ${ }^{(15,16)}$. Among them, Naderer et al.'s ${ }^{(13)}$ study indicated that healthy food placements in movies and TV do not automatically increase fruit consumption among children. Therefore, it is crucial to investigate what persuasive strategies in presenting healthy food placements can encourage children to make healthy food choices ${ }^{(17)}$.

To positively influence children's food choices in particular, one such strategy can be to highlight either the benefits of eating healthy foods (gain-framing) or the disadvantages of not doing so (loss-framing; ${ }^{16,18}$ ). For instance, if a campaign ad portrays the benefits of being physically active, then its viewers are more likely to become physically active after watching the ad. Likewise, 
emphasising the threats or negative outcomes (making lossframed arguments) of certain behaviours can motivate individuals to take health-related action by discontinuing those behaviours - for example, quitting smoking ${ }^{(19)}$. Which strategy more effectively elicits health-related actions, however, depends on the health behaviour. According to the Prospect Theory ${ }^{(20)}$, gain-framed messages more persuasively encourage preventative behaviours ${ }^{(21)}$, whereas loss-framed ones more persuasively encourage behaviours aimed at detecting health conditions ${ }^{(22)}$. Following that line of argumentation, emphasising the benefits of healthy eating (e.g. preventing obesity and illness) should be more effective in prompting healthier food choices than focusing on losses ${ }^{(23)}$.

However, despite the strong theoretical basis for this argument, there is a lack of studies investigating the effects of these framed messages in entertainment media on children's healthy eating behaviours. While there are very few studies on children's reactions to gain- and loss-framed public service announcements (PSA) ${ }^{(24)}$ or promotional videos $^{(23)}$, we completely lack studies on narrative, entertainment media. Bannon and Schwartz ${ }^{(23)}$ found that in a promotional context both gain and loss frames are equally effective in influencing children's fruit choice compared to not being exposed to a health message. However, the sample consisted of fifty children only. In another study, Wyllie and colleagues ${ }^{(24)}$ tested the impact of gain- and loss-framing in child-targeted PSA. The authors observed that, compared to children in the loss-framed condition, children who watched a PSA stressing the benefits of healthy eating (gain condition) exhibited positive attitudes towards fruit consumption and a clear intention to eat fruit. Nevertheless, the authors did not measure children's actual consumption behaviour after children viewed the stimuli. This is important because as studies on the influence of healthy food placements have shown, documenting actual behavioural responses to stimuli makes a big difference in order to observe effects ${ }^{(13)}$. Yet, announcement and promotional videos are entirely different in their reception and enjoyment of the reception than narrative, entertainment media that children select themselves. Additionally, although researchers have observed that exposure to healthy food placements in narrative content increased children's positive opinions about healthy food (e.g. ${ }^{24,25}$ ) and their intention to eat healthy (e.g. ${ }^{24,26}$ ), studies investigating actual eating behaviour did not find such an effect $^{(13)}$. Taken together, the findings suggest that food placements in narrative content can easily influence children's intention to eat healthy. However, influencing children's actual intake of healthy foods seems more difficult. The latter of which might require children's cognitive awareness of the specific characteristics of healthy foods.

The Reactivity of Embedded Food Cues in Advertising Model (REFCAM) describes that food cues in media prompt physiological and/or psychological responses (e.g. thinking about stated arguments) in a first step. Then, these physiological or psychological responses influence the actual food choices of audiences ${ }^{(15)}$. As described in dualprocess models, it might be possible that children need cognitive control in a first step ${ }^{(27)}$ to overcome their biological instinct to choose the sweet or salty but, in either case, unhealthy snack ${ }^{(28)}$. This cognitive control may be achieved with the awareness of gain- or loss-framed arguments about fruit. Only if children can consciously process the information they encounter - in this case, if they are aware of the gain- or loss-framed arguments - it is possible to influence children's fruit intake ${ }^{(29,30)}$. This leads to the first two hypotheses: Exposing children to gain- or loss-framed arguments about healthy eating should raise their awareness of those arguments (H1a), which could trigger their recall of the benefits of healthy eating before they encounter audio-visual cartoon movies with those arguments (H1b).

Also, according to REFCAM ${ }^{(15)}$, children more aware of arguments about fruit consumption should show a greater preference for fruit instead of candy. Added to that, the Prospect Theory ${ }^{(19)}$ maintains that, in general, gain-framed arguments should affect preventative behaviours (e.g. healthy eating) better than loss-framed arguments, or no argument (H2a). However, children's awareness of lossframed arguments about nutrition might encourage their healthy eating behaviour compared to not encountering any persuasive strategy at all (H2b).

When it comes to the effects of messages embedded in entertainment media on children, it is especially important to investigate the role of age, which can influence children's understanding of persuasive arguments. Researchers have indicated that children's ability to process information is subject to their cognitive skills, which develop over time at rates that vary from individual to individual $^{(31)}$. At the age of $2-5$ years, as children continue to develop their ability to process information, they struggle to remember and verbalise specific information (e.g. ${ }^{32}$ ). By mid-childhood (i.e. 6-9 years of age), however, children can process information and recall the content of messages $^{(32)}$; and at 10-12 years of age, they can also think and reason abstractly ${ }^{(33)}$. Thereafter, children have presumably developed adult-like information processing skills ${ }^{(32)}$. Following that trajectory of children's development, children's age could moderate their awareness of arguments made and, in turn, the effectiveness of any framed argument. One may assume that older children's improved information processing skills and thus greater awareness of argument types might make nutritional framed messages more effective. However, the effects of message framing among different age groups remain poorly understood. Hence, how age might moderate the effects of framing represents the first research question of this study (RQ1).

Research on children's dietary trends showed that parents can play a special role given their various, often unparalleled influence over children's eating habits, particularly via meal preparation (e.g. ${ }^{34}$ ) and the enforcement of eating rules ${ }^{(35,36)}$. In this context, it might be not only 
important which rules parents state but also how they communicate these rules. Although a common distinction in parental mediation style delineates active and restrictive styles $^{(37)}$, researchers have largely applied those concepts to clarify parents' role in children's media consumption. Whereas restrictive mediation involves communicating prohibitions and rules but not rationalising them for children, active mediation involves not only rationalising rules but also articulating possible consequences of violating them $^{(38)}$.

These mediation styles can be easily adapted concerning eating rules for children. Naderer et al. ${ }^{(13)}$ observed that children exposed to unhealthy food placements in cartoons and whose parents applied a low, average or mildly high active food-related mediation style are more likely to later choose an unhealthy snack compared to children not exposed to any food placements. They also noted that parents' active food-related mediation style directly affects their children's unhealthy food choices, arguably due to the so-called 'Forbidden Fruit Effect' of commodity theory ${ }^{(39)}$, which holds that people find seemingly unavailable goods more desirable ${ }^{(40)}$. Although the authors additionally found that applying a restrictive mediation style had no effects and that applying either mediation style had no effect on children exposed to healthy food placements only, they presented placements unaccompanied by persuasive strategies in their experiment. By contrast, using framed messages could exert a moderate effect on children's awareness of arguments provided their awareness of similar arguments made, for instance, at home. Given that active mediation styles have been proven to be more effective in the context of media consumption (e.g. ${ }^{41}$ ), applying an active mediation style with eating habits could influence the effectiveness of framed arguments on children's awareness of such arguments. To the best of our knowledge, however, no research has investigated those parental mediation styles in terms of the effectiveness of framed messages about eating healthy among children (RQ2).

This study investigated how audio-visual cartoons for children can present fruit to influence children's subsequent eating habits - namely, to prefer fruit instead of unhealthier food options. This study marks the first to examine stressing either the benefits of eating fruit (gain frame) or the disadvantages of not doing so (loss frame) in entertaining audio-visual content for children. Furthermore, no research to date has examined the moderating roles of children's individual susceptibility factors, including parent's food-related mediation styles (i.e. active $v$. restrictive ${ }^{37}$ ), or children's age as an indicator of their cognitive developmental stage. The present study attempts to fill those gaps in the literature. This experimental study with 6-10-year-old children (N161) tests the effectiveness of presentation of gain- $v$. loss-framed arguments about eating fruit. Then, whether children opted to eat fruit instead of candy after watching the cartoon was recorded.

The proposed model for the study is presented in Fig. 1.

\section{Method}

\section{Design}

Data for this study were collected from children in three primary schools in Austria during February and March 2018. The headmasters of the participating schools and the ethical committee of the University of Vienna approved the study. For each child, his or her oral consent to participate in the study was obtained. Additionally, the researchers collected parent's written consent for each child. Children were informed that they could withdraw their consent or withhold information at any point of the study. Each child watched one of three versions of an audio-visual cartoon. The cartoon showed no food placement (control

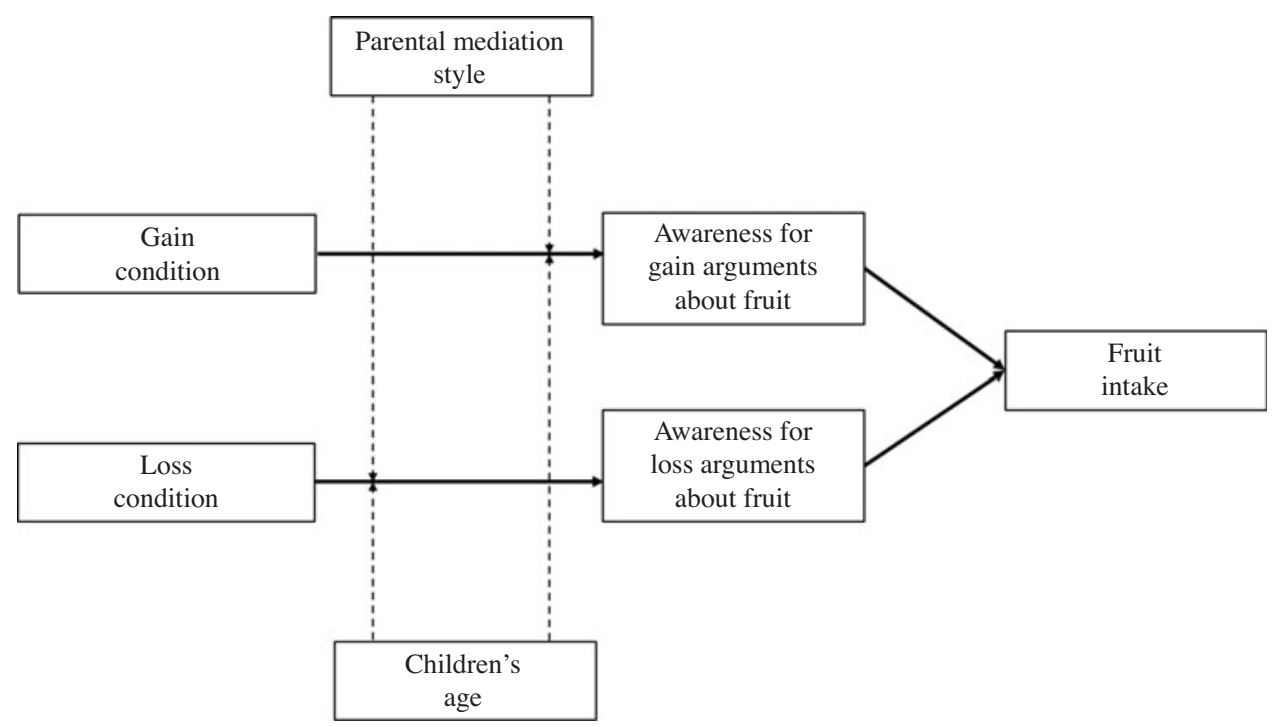

Fig. 1 Conceptualised model 
condition), or presented gain-framed arguments about eating fruit (gain-framed condition) or loss-framed arguments about not eating fruit (loss-framed condition; $\left.\operatorname{see}^{23}\right)$. After the children watched the cartoons, three researchers interviewed them individually and administered a snack choice test to assess their preference for fruit or candy subsequent to their exposure to the cartoons. To assess parental food-related mediation styles, experimental data of each child with the survey completed by his or her parent at home were matched.

\section{Participants}

The overall sample consisted of 178 children aged 6-10 years only, for several reasons. First, to ensure that participants would understand the message and could adequately process the stated information, no recruitment of children in early childhood took place (e.g. ${ }^{32}$ ). Second, children needed to have child-like information processing levels instead of adult-like ones; hence, no recruitment of children aged over 12 years took place ${ }^{(33)}$. Because parental indications were also potentially relevant, only datasets in which a parent had completed a questionnaire ( $n$ 166) were analysed. Datasets in which data relevant to the analysis were missing ( $n 2$ ), in which significant language difficulties occurred due to the family's migration background ( $n$ 1), and in which excessive briefing from the teacher or parents about the study's purpose rendered the participants' choices biased ( $n$ 2) were excluded. ${ }^{1}$ Ultimately, the complete datasets of 161 children ( $M_{\text {age }}=7.96$ years, $\mathrm{SD}=1.32 ; 47.2 \%$ girls $)$ with one parent each $\quad\left(M_{\text {age }}=40.86\right.$ years, $\quad \mathrm{SD}=6.53 ; 71.4 \%$ women $)$ remained in the final analysis.

\section{Procedure}

To avoid confounding variables in the classroom dynamics (e.g. whether and, if so, how the teacher had previously discussed healthy eating behaviour), each participating class was divided randomly into two groups. Children participated in groups of 4-10. Each group was exposed to one of the three versions of the audio-visual cartoon determined randomly, with one experimenter supervising each screening. After stimulus presentation, two children at a time entered two separate interview rooms, while the experimenter supervising the screening entertained the remaining children in the group. Before commencing the interviews, the interviewers thanked the children by offering them four different snacks: mandarins (embedded in the cartoon), grapes (embedded in the cartoon), fruit gummies and fruit chews. Mandarins and grapes present healthy snacks, whereas fruit gummies and fruit chews can be categorised as unhealthy alternatives. Each child was allowed to choose one of the four snacks, whose order

${ }^{1}$ The results stayed completely unaffected by the exclusion of those children. of presentation on the table was fully randomised. Lastly, the researchers conducted the interviews. Once the researchers had interviewed all children in one group, they returned to the classroom, and the next group proceeded into the screening room. To prevent undue influence of the children interviewed later, the researchers instructed all children not to talk about the snack options or their personal snack of choice; all children followed the briefing.

In a pre-test with another group of children (N21), it was ensured that the provided candy options were perceived as clearly unhealthy by children: $95.2 \%$ of children between 6 and 10 years stated that fruit gums and $100 \%$ of children stated that fruit chews can be classified as unhealthy. Likewise, the healthy options were seen as healthy foods (mandarins: $95.2 \%$; grapes: $95.2 \%$ ).

\section{Stimuli}

Three versions of a short cartoon movie, each ranging from 4:55 to 5:50 min in length, were designed using the software PowToon. In the cartoon, set on a vocational orientation day at a school, the school nurse, the physical education teacher and the school cook talked about their jobs. In their stories, none of the characters mentioned fruits (control group; $N 48$ ), or they mentioned the benefits of eating fruit (gain-framed condition; $N 55$ ), or the disadvantages of not eating fruit (loss-framed condition; $N 58$; see online supplementary material). All other aspects of the story stayed constant. Later, the three conditions were dummy-coded.

The cartoons in both gain-framed and loss-framed conditions integrated references to fruit nine times. In six of the nine instances, characters also mentioned a specific product; for example, in the gain-framed condition, a character stated, 'If you eat healthy - if you eat, for example, mandarins - then you'll have enough endurance to play with your friends', whereas in the loss-framed condition, a character stated, 'If you don't eat healthy - if you don't eat, for example, mandarins - then you won't have enough endurance to play with your friends.' The fruits were clearly visible.

\section{Measures}

\section{Dependent variable}

The dependent variable was children's intake of fruit or candy. As described, prior to interviews, children could choose one snack from four options - grapes, mandarins, fruit gummies or fruit chews, none of which had visible brands. Later, the choices were combined and the intake of fruit (i.e. grapes and mandarins) and that of candy (i.e. fruit gummies and fruit chews) were dummy-coded to compare the intake of fruit with the choice of candy.

\section{Mediator}

To test the children's awareness of gain- and loss-framed arguments as a mediating variable, the interviewer asked 
the children an open-ended question regarding what exactly they knew about fruit. The number of gain$(M=1.06, \mathrm{SD}=1 \cdot 02)$ or loss-framed $(M=0 \cdot 19, \mathrm{SD}=0.57)$ arguments each child named was recorded, whether the argument had appeared in the cartoon or not. To make sure that coding of gain and loss arguments was reliable, a reliability test between two researchers, on a subsample of 30 interviews (18.2\% of the sample), which yielded a sufficient reliability score for type of argument (Krippendorff's $\alpha=0.99$ ), was conducted.

\section{Moderators}

To test parents' food-related mediation styles (i.e. restrictive or active) as a moderator, a parent answered six items about nutritional mediation styles, each rated on a sevenpoint Likert scale $(1=$ seldom, $7=$ very often $)$. The items were based on established media mediation measurements of active and restrictive mediation strategies ${ }^{(13)}$. The six items were simultaneously entered into an explorative principal component analysis with oblique rotation. The analysis yielded two factors, explaining $68.46 \%$ of the variance. Three items represented restrictive food-related mediation: for example, 'I follow clear rules and restrictions on what my child is allowed to eat' (Cronbach's $\alpha=0.75$; $M=3.96, \mathrm{SD}=1.56$ ). By contrast, three others represented active food-related mediation: for example, 'I talk to my child about the consequences of unhealthy eating behaviour' (Cronbach's $\alpha=0.76 ; \quad M=6 \cdot 04, \mathrm{SD}=1 \cdot 00$ ). Both measures had acceptable internal consistency. To collect data on children's age, the interviewer simply asked each child how old he or she was during the interviews $(M=7 \cdot 96, \mathrm{SD}=1 \cdot 32)$.

\section{Results}

\section{Data analysis}

The proposed moderated mediation model with fruit intake as the dependent variable (dummy codes: $0=$ chose candy; $1=$ chose fruit), awareness of gain- or loss-framed arguments as mediators, and parent's food-related mediation style (i.e. active $v$. restrictive) and child's age as moderators was tested using SPSS Macro PROCESS, Model 4, involving 1000 bootstrap samples ${ }^{(42)}$. The control condition served as a reference group, and all continuous variables were meancentred. This procedure calculates two regression models. The first regression analysis is a linear regression that tests the effect of the independent variable (experimental group) on the mediator (awareness of gain- or loss-framed arguments). The second regression analysis is a logistic regression that tests the effects of the conditions and the mediator on the outcome variable (fruit intake).

\section{Randomisation checks}

Randomisation checks for gender $\left(\chi^{2}=0.57, \mathrm{df}=2\right.$, $n$ 161, $\Phi=0.06, P=0.754)$, age $(F(2,162)=0 \cdot 28, n 164$,
$P=0.755)$, restrictive parental mediation $(F(2,159)=0.04$, $n 161, P=0.961)$, active parental mediation $(F(2,159)=$ $0.67, n 161, P=0.505)$ and liking of the stimulus $(F(2,158)=2.52, n 161, P=0.084)$ achieved satisfactory results. Additionally, the overall liking of the audio-visual cartoons was very high (four-point scale; $M=3.56$, $\mathrm{SD}=0.62)$, which stressed the entertainment component of the employed stimuli.

\section{Manipulation checks}

To ensure that children could recognise which snacks appeared in the cartoon, the characters mentioned specific product names (e.g. 'mandarins' and 'grapes'). During interviews, whether children correctly remembered which products appeared in the cartoon was measured. In the gain-framed condition, $69.0 \%$ of children freely recalled the presented fruit (i.e. mandarins and grapes), as did $65.9 \%$ of children in the loss-framed condition. This difference was highly significant $(P<0 \cdot 001)$. In the control condition, as expected, no child named any fruit. Also, a recognition test with pictures of the embedded foods (i.e. mandarins and grapes) was conducted. In the gainframed condition, $96.4 \%$ of children correctly identified the mandarins, and $100.0 \%$ the grapes, while $93.1 \%$ and $100.0 \%$ of children in the loss-framed condition detected mandarins and grapes, respectively. In the control condition, two children thought that the cartoon presented mandarins, whereas another thought that it had presented grapes.

In the gain- and loss-framed conditions presenting fruit placements, children were additionally asked, 'How did the characters in the cartoon talk about fruit? Did they say what happens if you eat fruit or what happens if you don't eat fruit?' In the gain-framed condition, $92.6 \%$ of children replied that the characters had talked about the benefits of eating fruit, whereas $87.0 \%$ of children in the loss-framed condition said they had talked about the disadvantages of not eating fruit. This was a highly significant difference $(P<0.001)$. Thus, results of the manipulation check for the loss- and gain-framed arguments were satisfactory.

\section{Awareness of gain- and loss-framed arguments}

First, whether the conditions influenced awareness of gain- or loss-framed arguments was tested. Results showed that children in the gain-framed condition showed greater awareness of gain-framed arguments about a healthy nutrition $(b=1.05, P<0.001 ; \quad$ LLCI $=0.67 ; \quad$ ULICI $=1.44)$ compared to children in the control condition. Moreover, children in the gain-framed condition showed a significantly greater awareness of gain arguments $(b=0.70$, $P<0 \cdot 001 ;$ LLCI $=0 \cdot 35$; ULICI $=1 \cdot 06$ ) compared to children in the loss-framed condition. H1a found full support. Additionally, no significant difference emerged between children in the loss-framed and control conditions $(b=-0.35, \quad P=0.067 ; \quad$ LLCI $=-0.72 ; \quad$ ULICI $=0.02)$ 
Table 1 Full effect model

\begin{tabular}{|c|c|c|c|c|c|c|}
\hline & \multicolumn{2}{|c|}{$\begin{array}{l}\text { Awareness for gain } \\
\text { arguments }\end{array}$} & \multicolumn{2}{|c|}{$\begin{array}{l}\text { Awareness for loss } \\
\text { arguments }\end{array}$} & \multicolumn{2}{|c|}{ Fruit intake } \\
\hline & $b$ & SE & $b$ & SE & $b$ & SE \\
\hline Gain condition & $1.05^{\star \star \star}$ & 0.19 & 0.02 & 0.10 & $1 \cdot 14^{*}$ & 0.53 \\
\hline Loss condition & $0.35 \dagger$ & 0.19 & $0.45^{\star \star \star}$ & 0.10 & 0.94 & 0.53 \\
\hline Age & 0.03 & 0.11 & 0.00 & 0.05 & 0.22 & 0.29 \\
\hline Active mediation ${ }^{a}$ & 0.01 & 0.15 & 0.00 & 0.08 & -0.20 & 0.38 \\
\hline Restrictive mediation ${ }^{\mathrm{b}}$ & -0.00 & $0 \cdot 10$ & 0.00 & 0.05 & -0.15 & 0.28 \\
\hline Gain condition $\times$ age & -0.06 & 0.15 & 0.02 & 0.08 & 0.15 & 0.38 \\
\hline Loss condition $\times$ age & 0.06 & 0.14 & 0.05 & 0.07 & -0.04 & 0.38 \\
\hline Gain condition $\times$ active mediation & -0.04 & 0.20 & -0.06 & $0 \cdot 10$ & 0.22 & 0.48 \\
\hline Loss condition $\times$ active mediation & -0.10 & 0.21 & 0.01 & 0.11 & $-0 \cdot 10$ & 0.53 \\
\hline Gain condition $\times$ restrictive mediation & 0.06 & 0.14 & 0.01 & 0.07 & $0 \cdot 10$ & 0.36 \\
\hline Loss condition $\times$ restrictive mediation & -0.17 & 0.13 & 0.08 & 0.07 & 0.23 & 0.35 \\
\hline Awareness for gain arguments & & & & & $0.58^{* *}$ & 0.21 \\
\hline Awareness for loss arguments & \multirow{2}{*}{\multicolumn{2}{|c|}{0.22}} & & & 0.32 & 0.36 \\
\hline Explained variance & & & \multicolumn{2}{|c|}{0.20} & \multicolumn{2}{|c|}{0.14} \\
\hline
\end{tabular}

Macro PROCESS 3, Model 4 with 1000 bootstrap samples; $N 156$.

Effects for awareness of gain/loss arguments based on a linear regression model; effects for fruit intake based on a logistic regression model.

Control condition inserted as a reference group.

${ }^{\star \star \star} P<0.001 ;{ }^{\star \star} P<0.01 ;{ }^{*} P<0.05 ; \dagger P<0.07$.

†Active food-related mediation

†Restrictive food-related mediation.

concerning awareness of gain-framed arguments. Children in the loss-framed condition tended to know slightly more gain-framed arguments than children in the control condition, yet the effect did not reach significance $(P=0.067$; Table 1).

Regarding H1b, children in the loss-framed condition were significantly more aware of loss-framed arguments about not eating fruit $(b=0.45, P<0.001 ;$ LLCI $=0.27$; ULICI $=0.65)$ compared to children in the control condition, and demonstrated significantly greater awareness of loss-framed arguments compared to children in the gainframed condition $(b=-0.43, \quad P<0.001 ; \quad$ LLCI $=-0.62$; ULICI $=-0 \cdot 25$; Table 1$)$.

\section{Child's age and parent's food-related mediation styles}

Neither child's age nor parent's food-related mediation styles (active and restrictive) exerted any primary effects on the children's awareness of gain- or loss-framed arguments or on their choosing fruit as a snack. To answer RQ1 and RQ2, we tested whether child's age or parent's food-related mediation styles moderated the effects of the child's awareness of gain- or loss-framed arguments, neither of which did.

\section{Choice of fruit}

The results showed that children's choice of fruit instead of candy depended significantly on their awareness of gainframed arguments concerning personal nutrition. If children showed greater awareness of such arguments, then they were more likely to choose fruit instead of candy during interviews $(b=0.58, P=0.005$; LLCI $=0.17$;
ULICI $=0.98$ ). The awareness of loss-framed arguments concerning not eating fruit, however, did not influence whether children chose fruit $(b=0.32, \quad P=0.375$; $\mathrm{LLCI}=-0 \cdot 38$; ULICI $=1 \cdot 02$ ). Additionally, a direct positive effect of the gain-framed condition on children's choice of fruit was present - children in that condition were more likely to choose fruit $(b=1 \cdot 14, P=0.032 ;$ LLCI $=0 \cdot 10$; ULICI $=2 \cdot 19)$ compared to children in the control condition. However, there were no significant direct effects on childrens' fruit intake when comparing the experimental conditions $(b=0.20, \quad P=0.657 ; \quad$ LLCI $=-0.69$; ULICI $=1 \cdot 10$ ), and no direct effect emerged when comparing loss-framed and control conditions $(b=0.94, P=0.076$; $\mathrm{LLCI}=-0 \cdot 10$; ULICI $=1.98$ ). Thus, H2a can only be partly supported, whereas $\mathrm{H} 2 \mathrm{~b}$ has to be rejected. However, in all groups, the tendency to choose fruit instead of candy was rather low (control group: 19.1\%; gain-framed condition: $52.7 \%$; loss-framed condition: $43.9 \%$ ).

In a mediation test involving 1000 bootstrap samples, however, a mediation effect was found: an indirect effect of the gain-framed condition on children's choosing fruit mediated by their awareness of gain-framed arguments about eating fruit $(b=0.61$; LLCI $=0.04 ;$ ULICI $=1 \cdot 14)$. Conversely, no such indirect effect of the loss-framed condition on children's choosing fruit mediated by their awareness of loss-framed arguments about not eating fruit occurred $(b=0 \cdot 14 ;$ LLCI $=-0.33$; ULICI $=0.55)$.

Overall, these findings indicate that children in the gainframed condition were more aware of gain-framed arguments for eating fruit, which made them more likely to choose fruit instead of candy compared to children in the loss-framed or control conditions. In the loss-framed condition, children were more aware of loss-framed 
arguments about not eating fruit compared to the gainframed and control conditions; however, such an awareness did not make them more likely to choose fruit instead of candy compared to children in the gain-framed or control conditions. Although the same model using the gain-framed or loss-framed condition as a reference group was tested, no additional effects occurred.

\section{Discussion}

Overall, this study showed that the framing of nutritional messages in cartoon movies can positively influence children's fruit intake. The results are in line with the Prospect Theory ${ }^{(19)}$ and the results of a recent meta-analysis ${ }^{(43)}$; gain-framing such messages within cartoon movies seems to be more effective on children when they have to choose either fruit or candy as a snack.

The gain-framed condition generated greater awareness of gain-framed arguments than the loss-framed and control conditions. At the same time, the loss-framed condition prompted greater awareness of loss-framed arguments than the gain-framed and control conditions. On a cognitive level, both experimental conditions seemed to be equally effective. However, when looking at the absolute number of stated arguments, overall, it seems to be easier for children to state gain arguments compared to loss arguments. Additionally, only the awareness of gain-framed arguments prompted a greater likelihood of choosing fruit instead of candy after encountering the stimuli. This effect was not present for the awareness of lossframed arguments. Accordingly, children in the gainframed condition demonstrated greater awareness of gain-framed arguments, which in turn made them more likely to choose fruit instead of candy compared to children in the control and loss-framed conditions. These results are in line with the Prospect Theory, which states that gainframing is more effective for preventative behaviour ${ }^{(19)}$. This prediction is based on the assumption that there is a difference in the perceived level of risk between the two types of behaviours. Detection behaviours (e.g. getting a mammogram) are considered risky because they involve the detection of an illness, which comes with psychological and financial costs. Whereas prevention behaviours (e.g. healthy nutrition) are considered less risky because little cost is involved in performing the behaviour, and not engaging in such behaviours could be risky ${ }^{(20,44)}$. Thus, gain-framed messages are especially effective for preventative behaviours $^{(21)}$, whereas loss-framed messages are more effective for detection behaviours (e.g. ${ }^{22,45}$ ).

Additionally, compared to the control condition, the gain-framed condition exerted a positive, direct effect on children's choosing fruit and can influence children's preference for fruit in a positive way. Surprisingly, however, neither parent's food-related mediation styles nor child's age influenced those effects. Such findings suggest that children aged 6-10 years can increase their awareness of framed arguments about eating healthy independent of their cognitive development and of their parent's food-related mediation styles and, in turn, be equally positively influenced by them. However, to gain an insight into the role of age in this context, it is important to conduct a meta-analysis.

This study ranks among the first in the field to isolate an effective persuasive strategy to positively influence children's choice for fruit over candy. However, more research is needed to understand the underlying process of that influence, and the results particularly showed that children's information processing warrants a close attention ${ }^{(29)}$. Only the awareness of gain-framed arguments, but not that of loss-framed arguments, shapes children's healthy food choices. Thus, gain-framing seems to be more powerful for preventative behaviours that approach an object (i.e. selecting healthy food). However, another mediator could also shed light on the direct effect of the gain-framed condition on children's choice of fruit compared to the control condition. Gallagher and Upedgraff ${ }^{(43)}$ have posited that in measuring behaviour as an outcome variable, mediators such as self-efficacy, social norms, outcome expectancies or positive emotions might also be crucial. Researchers should test those additional mediators to elucidate why gain-framed messages are more effective than loss-framed ones when presenting nutritional messages to children about fruit.

When only testing the direct effects of the conditions on children's choice of fruit over candy, excluding all moderators and mediators also, the loss condition showed a direct effect compared to the control condition $(b=0 \cdot 32$, $P=0.015)$. However, the gain condition was even more effective compared to the control condition $(b=0 \cdot 22$, $P<0.001)$. Although the framing of arguments regarding fruit can enhance children's healthy food choices in spontaneous situations presenting such choices, only half of all children in the gain-framed condition chose fruit instead of candy. Consequently, it remains necessary to consider how to present fruit even more positively to help children make healthy food choices.

\section{Limitations}

This study comes with some limitations. First, a direct as well as a mediated effect of awareness of gain-framed arguments on children's choice of fruit was found. Therefore, it is possible that another mediator not considered in this study might explain this direct effect. As mentioned above, measures such as positive emotion might clarify whether positive gain-framed arguments can also elicit positive emotions $^{(46)}$. In addition, while this study gave some insights on the processes described in $\operatorname{REFCAM}^{(15)}$, it is important to test additional explicit and implicit mediators as well as other susceptibility factors. Additionally, further studies should consider also asking parents regarding 
children's age to ensure the correctness of this information. Second, since the audio-visual stimuli presented fruit only, only conclusions for that food category are possible. Nevertheless, it would be interesting to conduct more research with other food groups, such as vegetables, because vegetables are also important for a healthy $\operatorname{diet}^{(1)}$. Third, because children's food choices were tested immediately after exposing them to the stimuli, no insights into the longevity of the positive effects of gain-framed messages ${ }^{(47)}$ were gained. Longitudinal research remains necessary.

\section{Conclusion}

This study provides important insights into how audio-visual entertainment media should present fruit to influence children's fruit intake in a positive way. Randomisation and manipulation checks showed satisfactory results, which represent clear strengths of the study. Additionally, in this study, the researchers created the stimuli in order to secure high levels of internal validity. In terms of external validity, all stimuli were based on real-life examples of childappropriate content. For instance, there are several episodes in 'Alvin and the Chipmunks' where the advantages of eating healthy are showcased. The nutritional messages used in the study are, therefore, highly externally valid. Creators of such content can profit from research investigating how such arguments should be framed to influence children positively. Since gain- and loss-framing can affect children on a cognitive level - teaching them about the benefits of eating fruit can significantly affect their preference for fruit. Although gain-framing was more effective at influencing children's food choices, in line with the Prospect Theory ${ }^{(19)}$, that persuasive strategy prompted only $52.7 \%$ of children in the gain-framed condition to choose fruit instead of candy. Therefore, more research is needed to investigate additional persuasive strategies in order to overcome children's biologically determined preference ${ }^{(28)}$ for eating sweet and salty foods. Also, the inclusion of additional mediators is needed to comprehensively clarify why gain-framing can more effectively convey nutritional messages to children. There are already school programmes in many countries trying to influence children's health behaviour in a positive way. This study suggests that such programmes should include entertainment media as an effective way of informing children about changing their health behaviours.

\section{Acknowledgements}

Acknowledgements: We wish to thank Michaela Forrai and Sarah Ecklebe for their help in conducting the experiment, and Thomas Naderer for his help with the stimulus materials. Financial support: This project was funded by the Central Bank of the Republic of Austria, grant ID 17715. The Central Bank of the Republic of Austria had no role in the design, analysis or writing of this article. Conflict of interest: None. Authorship: Alice Binder conceptualised the study, collected data, designed data collection instruments, carried out the initial analysis and drafted the initial manuscript. Brigitte Naderer designed data collection instruments, collected data and reviewed and revised the manuscript. Jörg Matthes supervised data collection instruments, data collection and reviewed and revised the manuscript. All authors approved the final manuscript as submitted and agree to be accountable for all aspects of the work. Ethics of buman subject participation: This study was conducted according to the guidelines laid down in the Declaration of Helsinki, and all procedures involving study participants were approved by the ethical committee of the University of Vienna. For each child, his or her oral consent to participate in the study as well as his or her parent's written consent was obtained.

\section{Supplementary material}

For supplementary material accompanying this article visit https://doi.org/10.1017/S1368980019004683

\section{References}

1. WHO - World Health Organization (2016) Obesity and Overweight. Factsheet June 2016. http://www.who.int/ mediacentre/factsheets/fs311/en/ (accessed February 2018).

2. WHO - World Health Organization (2003) Promoting Fruit and Vegetable Consumption around the World. http:// www.who.int/dietphysicalactivity/fruit/en/ (accessed September 2018).

3. Lin BH \& Morrison RM (2002) Higher fruit consumption linked with lower body mass index. Food Rev 25, Suppl. 3, S28-S32.

4. Wang Y \& Lobstein T (2006) Worldwide trends in childhood overweight and obesity. Int J Pediatr Obes 1, 11-25.

5. St-Onge MP, Keller KL, Heymsfield SB (2003) Changes in childhood food consumption patterns: a cause for concern in light of increasing body weights. Am J Clin Nutr 78, 1068-1073.

6. Yngve A, Wolf A, Poortvliet E et al. (2005) Fruit and vegetable intake in a sample of 11-year-old children in 9 European countries: the pro children cross-sectional survey. Ann Nutr Metab 49, Suppl. 4, S236-S245.

7. Eggermont S \& Roe K (2014) Television and risk behaviorcontemporary perspectives. J Child Media $\mathbf{8}$, Suppl. 1, S1-S4.

8. Auty S \& Lewis C (2004) Exploring children's choice: the reminder effect of product placement. Psychol Market 21, Suppl. 9, S697-S713.

9. Folkvord F, Anschütz DJ, Buijzen M et al. (2013) The effect of playing advergames that promote energy-dense snacks or fruit on actual food intake among children. Am J Clin Nutr 97, Suppl. 2, S239-S245.

10. Folkvord F, Anschütz DJ, Nederkoorn C et al. (2014). Impulsivity, 'advergames,' and food intake. Pediatrics 133, Suppl. 6, S1007-S1012.

11. Halford JCG, Boyland EJ, Hughes GM et al. (2008) Beyondbrand effect of television food advertisements on food choice in children. The effects of weight status. Public Health Nutr 11, Suppl. 9, S897-S904 
12. Matthes J \& Naderer B (2015) Children's consumption behavior in response to food product placements in movies. J Consum Behav 14, Suppl. 2, S127-S136.

13. Naderer B, Matthes J, Binder, A et al. (2018) Shaping children's healthy eating habits with food placements? Food placements of high and low nutritional value in cartoons, children's BMI, food-related parental mediation strategies, and food choice. Appetite 120, S644-S653.

14. Naderer B, Matthes J \& Zeller P (2018) Placing snacks in children's movies: cognitive, evaluative, and conative effects of product placements with character product interaction. Int J Advert 37, Suppl. 6, S852-S870.

15. Folkvord F, Anschütz DJ, Boyland E et al. (2016) Food advertising and eating behavior in children. Curr Opin Behav Sci 2016, Suppl. 9, S26-31.

16. O'Keefe DJ \& Jensen JD (2007) The relative persuasiveness of gain-framed and loss-framed messages for encouraging disease prevention behaviors: a meta-analytic review. J Health Commun 12, Suppl. 7, S623-S644.

17. Utter J, Scragg R \& Schaaf D (2006) Associations between television viewing and consumption of commonly advertised foods among New Zealand children and young adolescents. Public Health Nutr 9, S606-S612.

18. O'Keefe DJ \& Jensen JD (2009) The relative persuasiveness of gain-framed and loss-framed messages for encouraging disease detection behaviors: a meta-analytic review. J Commun 59, Suppl. 2, S296-S316.

19. Kahneman D \& Tversky A (1979) Prospect theory: an analysis of decision under risk. Econometrica 47, S263-S291.

20. Rothman AJ \& Salovey P (1997) Shaping perceptions to motivate healthy behavior: the role of message framing. Psychol Bull 121, Suppl. 1, S3-S19.

21. Hwang Y, Cho H, Sands L et al. (2011) Effects of gain-and loss-framed messages on the sun safety behavior of adolescents: the moderating role of risk perceptions. J Health Psychol 17, Suppl. 6, S929-S940.

22. Apanovitch AM, McCarthy D \& Salovey P (2003) Using message framing to motivate HIV testing among low-income, ethnic minority women. Health Psychol 22, Suppl. 1, S60-S67. doi: 10.1037/0278-6133.22.1.60

23. Bannon K \& Schwartz MB (2006) Impact of nutrition messages on children's food choice: pilot study. Appetite $\mathbf{4 6}$, Suppl. 2, S124-S129.

24. Wyllie J, Baxter S \& Kulczynski A (2015) Healthy kids: examining the effect of message framing and polarity on children's attitudes and behavioral intentions. J Advert 44, Suppl. 2, S140-S150.

25. Charry KM (2014) Product placement and the promotion of healthy food to pre-adolescents: when popular TV series make carrots look cool. Int J Advert 33, Suppl. 3, S599-S616.

26. Harris JL, Speers SE, Schwartz MB et al. (2012) US food company branded advergames on the internet: children's exposure and effects on snack consumption. J Child Media 6, Suppl. 1, S51-S68

27. Sherman JW, Gawronski B, Gonsalkorale K et al. (2008) The self-regulation of automatic associations and behavioral impulses. Psychol Rev 115, Suppl. 2, S314-S335.

28. Birch LL \& Marlin DW (1982) I don't like it; I never tried it: effects of exposure on two-year-old children's food preferences. Appetite 3, S353-S360.

29. Nairn A \& Fine C (2008) Who's messing with my mind? The implications of dual-process models for the ethics of advertising to children. Int J Advert 27, 447-470.
30. Naderer B, Binder A, Matthes J et al. (2020) Healthy, sweet, brightly colored, and full of vitamins: cognitive and affective persuasive cues of food placements and children's healthy eating behavior. Int J Advert, 1-19.

31. McAlister AR \& Cornwell TB (2009) Preschool children's persuasion knowledge: the contribution of theory of mind. J Public Policy Mark 28, Suppl. 2, S175-S185.

32. John DR (1999) Consumer socialization of children: a retrospective look at twenty-five years of research. J Consum Res 26, Suppl. 3, S183-S213.

33. Valkenburg PM (2004) Children's Responses to the Screen: A Media Psychological Approach. Mahwah, NJ: Lawrence Erlbaum.

34. Gage H, Egan B, Williams P et al. (2017) Importance of mental performance in parental choice of food for children aged 4-10 years: a study in four European countries. Public Health Nutr 20, Suppl. 6, S992-S1000.

35. Birch LL \& Fisher JO (1998) Development of eating behaviors among children and adolescents. Pediatrics 101, Suppl. 2, S539-S549.

36. Birch LL, Fisher JO, Grimm-Thomas K et al. (2001) Confirmatory factor analysis of the child feeding questionnaire: a measure of parental attitudes, beliefs and practices about child feeding and obesity proneness. Appetite 36, Suppl. 3, S201-S210.

37. Buijzen M \& Valkenburg PM (2005) Parental mediation of undesired advertising effects. J Broadcast Electron Media 49, Suppl. 2, S153-S165.

38. Borzekowski DLG \& Robinson TN (2001) The 30-second effect: an experiment revealing the impact of television commercials on food preferences of preschoolers. J Am Diet Assoc 101, Suppl. 1, S42-S46.

39. Gosselt JF, De Jong MD \& Van Hoof JJ (2012) Effects of media ratings on children and adolescents: a litmus test of the forbidden fruit effect. J Commun 62, Suppl. 6, S1084-S1101.

40. Lynn M (1991) Scarcity effects on value: a quantitative review of the commodity theory literature. Psychol Market 8, Suppl. 1, S43-S57.

41. Buijzen M (2009) The effectiveness of parental communication in modifying the relation between food advertising and children's consumption behaviour. Br J Dev Psychol 27, Suppl. 1, S105-S121.

42. Hayes AF (2013) Introduction to Mediation, Moderation, and Conditional Process Analysis: A Regression-Based Approach. New York, London: Guilford Press.

43. Gallagher KM \& Updegraff JA (2011) Health message framing effects on attitudes, intentions, and behavior: a meta-analytic review. Ann Behav Med 43, Suppl. 1, S101-S116.

44. Rivers SE, Salovey P, Pizarro DA et al. (2005) Message framing and pap test utilization among women attending a community health clinic. J Health Psychol 10, Suppl. 1, S65-S77.

45. Schneider TR, Salovey P, Apanovitch AM et al. (2001) The effects of message framing and ethnic targeting on mammography use among low-income women. Health Psychol 20, Suppl. 4, S256-S266. doi: 10.1037//0278-6133.20.4.256

46. Wegener DT, Petty RE \& Smith SM (1995) Positive mood can increase or decrease message scrutiny: the hedonic contingency view of mood on message processing. $J$ Pers Soc Psychol 69, Suppl. 1, S5-S15.

47. Arendt F, Naderer B, Abdollahi M et al. (2015) Television commercials and fading behavioral brand choice effects in Austrian children. J Child Media 9, Suppl. 4, S435-S452. 